BULLETIN Bulletin hispanique

HispaniQuE Université Michel de Montaigne Bordeaux

121-2 | 2019

Representaciones de autor (XV-XIX). Retratos, biografías, polémicas

\title{
Isaac del Vando Villar, La sombrilla japonesa y otros textos
}

Sevilla, Ulises, 2019

Jacques Issorel

\section{OpenEdition \\ Journals}

Édition électronique

URL : https://journals.openedition.org/bulletinhispanique/9707

DOI : 10.4000/bulletinhispanique.9707

ISSN : $1775-3821$

Éditeur

Presses universitaires de Bordeaux

\section{Édition imprimée}

Date de publication : 18 décembre 2019

Pagination : 746-748

ISBN : 979-10-300-0507-3

ISSN : 0007-4640

\section{Référence électronique}

Jacques Issorel, «Isaac del Vando Villar, La sombrilla japonesa y otros textos», Bulletin hispanique [En ligne], 121-2 | 2019, mis en ligne le 10 décembre 2019, consulté le 10 janvier 2023. URL : http:// journals.openedition.org/bulletinhispanique/9707; DOI : https://doi.org/10.4000/bulletinhispanique. 9707

Ce document a été généré automatiquement le 10 janvier 2023.

Tous droits réservés 


\title{
Isaac del Vando Villar, La sombrilla japonesa y otros textos
}

\author{
Sevilla, Ulises, 2019
}

Jacques Issorel

\section{RÉFÉRENCE}

Isaac del Vando Villar, La sombrilla japonesa y otros textos, ed. de José María BARRERA LóPEZ y Rogelio REYES CANO. - Sevilla, Ulises, 2019, 167 p. (Avant-garde, 4).

1 Isaac del Vando Villar a trente-quatre ans quand il publie en 1924 la première édition de La sombrilla japonesa, suivie la même année d'une deuxième édition. Il recueille dans ce livre une partie des poèmes qui ont déjà vu le jour dans la revue Grecia qu'il a luimême fondée, six ans auparavant à Séville, en étroite collaboration avec son mentor et ami, Adriano del Valle. C'est ce dernier qui lui a fait découvrir dès 1912 les mouvements d'avant-garde : futurisme, cubisme, dadaïsme, expressionnisme. Grecia, dont Isaac est l'ardent directeur et Adriano le rédacteur en chef, réunit dans ses pages les principaux représentants d'un nouveau mouvement littéraire et artistique, l'ultraïsme, dont le but est de promouvoir un art nouveau, en consonance avec les avant-gardes européennes, et de rompre avec les "patrones estéticos del "fin del siglo" " (p. 14). Les modèles de ces jeunes poètes sont Huidobro, Mallarmé, Apollinaire.

2 Parmi les collaborateurs de la revue on trouve Rafael Cansinos-Assens (inventeur du terme ultraísmo), Pedro Garfias, Rafael Lasso de la Vega, Gerardo Diego, Jorge Luis Borges, Ramón Gómez de la Serna, Guillermo de Torre et même... Federico García Lorca. Grecia publie également les textes traduits de la fine fleur de l'avant-garde européenne : Marinetti, Apollinaire, Breton, Cocteau, Max Jacob, Reverdy, Tzara, entre autres. Des artistes tels qu'Alfonso Grosso, Gutiérrez Solana, Norah Borges ou Sonia Delaunay y laissent aussi leurs signatures. Le succès remporté par la revue est attesté par le rythme de ses numéros : cinquante entre le 12 octobre 1918 et le $1^{\text {er }}$ novembre 1920 . À cette date Isaac et la revue qu'il dirige se sont déjà transportés à Madrid. À peine Grecia cesse- 
t-elle de paraître que naît Tableros, une nouvelle revue encore dirigée par l'infatigable del Vando, mais qui sombre après le quatrième numéro.

Précédé d'une flatteuse réputation littéraire, celui en qui $E l$ Liberal de Séville voit le «representante de la más moderna de las tendancias poéticas» (p.23) fait en 1922 en Uruguay et en Argentine un voyage aussi triomphal que peu rémunérateur. À court d'argent au bout de quelques mois, Isaac est rapatrié par le consulat d'Espagne à Buenos Aires. Loin de se laisser abattre, il prépare à son retour l'édition de La sombrilla japonesa, où il recueille vingt-cinq poèmes, pour la plupart déjà publiés dans Grecia ou dans Ultra. Chacun d'eux est dédié à un écrivain ou un artiste ami. Parmi ceux-ci on remarque les noms de Juan Ramón Jiménez, Federico García Lorca, Ramón Gómez de la Serna, Antonio Machado, José Ortega y Gasset, Valle-Inclán, Alfonso Reyes ou Fernando Villalón, désigné par son titre nobiliaire : "Conde de Miraflores de los Ángeles ». L'accueil réservé à La sombrilla japonesa est mitigé. Fernando Pessoa, Antonio Espina, Antonio Machado («Es lo más interesante que se publica hoy en España », p. 23) ne cachent pas leur admiration. En revanche, Juan Ramón, Ortega y Gasset et Gerardo Diego ( A Acabo de recibir el delicioso libro de Isaac. Me he reído a mandíbula batiente », lettre à J. Larrea, n. 57, p. 46) se montrent plus que réservés.

Pour les deux auteurs de l'ouvrage ici commenté La sombrilla japonesa est « un libro de desigual factura », mais innovateur et représentatif de "la variedad de motivos temáticos $y$ recursos formales » du mouvement ultraïste (p. 52). Ils remarquent toutefois l'absence de "una línea argumental vertebradora" (p.53). Pour notre part, nous avons apprécié la richesse métaphorique du recueil ( La tarde, equilibrista japonesa / ha cerrado su sombrilla de colores", "Puerto", p. 87); la vibration lyrique de "lo popular andaluz» (p. 52): "Quisiera ser como el aire, / para besarla en la frente, / sin que lo supiera nadie» (p. 95); les deux longs poèmes "El poema de la calle de las Sierpes» et «El poema de las Delicias Viejas", empreints tous deux du charme subtil de la "Ciudad de la Gracia»; ou bien encore des distiques tels que: "Las camareros visten de luto / por nosotros sus víctimas » ("Kursaal », p. 117), dignes du meilleur Gómez de la Serna.

5 Tous deux professeurs à l'Université de Séville, les deux éditeurs reconnaissent à Isaac del Vando Villar et à Grecia le mérite d'avoir apporté à Séville un « revulsivo y estímulo para futuras aventuras literarias ", en préparant le terrain pour les revues Mediodía (1926) et Papel de Aleluyas (Huelva-Séville, 1927-1928) et aussi pour les « veladas » de l'Ateneo en l'honneur de Góngora (décembre 1927).

6 Seize textes, en prose pour la plupart, publiés par del Vando dans Grecia ou dans $E l$ Liberal (Séville) entre 1919 et 1924, font suite à La sombrilla japonesa. Dans une langue aux accents souvent modernistes l'auteur y exprime une pensée originale et crée des moments d'émotion lorsqu'il met en scène sa mère (« El canto a la madre », pp. 124-126). Il évoque aussi avec splendeur la gestuelle de la fameuse danseuse Tórtola Valencia (1882-1955), « voluptuosamente lúbrica y nerviosa » (p. 149). Une bibliographie (pp. 60-66) et cinquante-trois notes complètent utilement cet ouvrage très élégamment présenté. 


\section{AUTEURS}

JACQUES ISSOREL

Université de Perpignan 